\title{
PERILAKU KONSUMEN RITEL MODERN AKAN KANTONG PLASTIK BERBAYAR
}

\author{
Suharmiati ${ }^{1}$, Budi Harni ${ }^{2}$ \\ STIE Kesatuan Bogor ${ }^{1}$ \\ Email: drasuharmiati@gmail.com \\ STIE Kesatuan Bogor ${ }^{2}$ \\ Email:budi_harni@yahoo.com
}

\begin{abstract}
ABSTRAK
Penelitian ini bertujuan untuk mengetahui perilaku konsumen ritel modern akan penggunaan kantong plastik dalam berbelanja di toko ritel modern Indonesia. Tujuan yang kedua dari penelitian ini adalah untuk mengetahui persepsi konsumen akan produk dan harga dari produk kantong kemasan belanja ramah lingkungan. Tujuan yang ketiga adalah untuk mengetahui peluang bisnis kantong kemasan belanja ramah lingkungan. Sampel dipilih dengan menggunakan teknik non-probabilitas yakni convenience sampling dengan ukuran sampel adalah sebanyak 200 responden. Teknik pengumpulan data menggunakan instrumen kuesioner dengan teknik analisis data menggunakan analisis data deskriptif dan metode analisis perbandingan sampel berpasangan nonparametrik. Berdasarkan hasil analisis datadiketahui bahwa perilaku konsumen yang menjadi responden penelitian ini adalah tidak atau belum tergerak untuk berinisiatif membawa kantong kemasan belanja sendiri, ketika berbelanja di toko ritel modern.
\end{abstract}

Kata Kunci: Peluang Bisnis, Perilaku Konsumen Ritel, Kantong Belanja, Lingkungan hidup

\section{ABSTRACT}

This study aims to determine the behavior of modern retail consumers will use plastic bags in shopping at modern retail stores Indonesia. The second goal of this research is to know consumer perception of product and price from environmentally friendly shopping bag packaging product. The third objective is to know the business opportunity of environmentally friendly shopping bags. Samples were chosen using non-probability technique ie convenience sampling with sample size was 200 respondents. Data collection techniques used questionnaire instruments with data analysis techniques using descriptive data analysis and non-parametric paired sample comparison analysis methods. Based on the results of the analysis datadiketahui that consumer behavior is the respondents of this research is not or have not moved to take the initiative to carry their own shopping bags, when shopping at modern retail stores.

Keywords: Business Opportunities, Retail Consumer Behavior, Shopping Bags, Environment

\section{PENDAHULUAN}

Penggunaan kantong plastik sebagai wadah pengemasan barang-barang belanja konsumen di berbagai jenis toko ritel, mulai dari ritel modern hingga ritel tradisional, sangat mudah ditemui dan menjadi kebiasaan yang dianggap wajar oleh sebagian masyarakat. Salah satu fenomena yang mucul adalah konsumen kerap menggunakan kantong plastik ganda pada saat di kasir, dengan alasan agar lebih kuat dan tidak mudah sobek. Jika fenomena ini dibiarkan terus menerus, maka penggunaan kantong plastik di Indonesia akan semakin mengkhawatirkan. Hal ini mengingat kantong plastik itu sulit terurai oleh proses dekomposisi alam, sehingga sangat berbahaya bagi kelestarian lingkungan hidup. 
Kondisi ini akan membutuhkan waktu yang lebih lama lagi, apabila kantong plastik tersebut berada di dalam air. Chairul, M. (2008) sebagaimana dikutip dalam laman http://www.menlh.go.id/ diakses pada tanggal 1 Mei 2016 mengatakan bahwa dari seluruh volume sampah yang ada, terdapat porsi rata-rata sebesar $10 \%$ kontribusi dari sampah plastik yang pada umumnya tidak dapat didaur ulang. Fenomena konsumsi plastik yang sangat berlebihan dan potensi bahaya yang dapat ditimbulkan dari plastik bagi kesehatan maupun kelestarian lingkungan hidup, menyebabkan pemerintah harus mengambil kebijakan di sektor hulu maupun hilir. Salah satu upaya pemerintah untuk mengatasi hal tersebut adalah dengan berfokus di salah satu hilir konsumsi penggunaan kantong plastik, yakni pada distribusi barang di tingkat eceran (retail).

Pemerintah melalui Kementerian Lingkungan Hidup dan Kehutanan mengeluarkan surat edaran Nomor S.1230/PSLB3-PS/2016 tentang Harga dan Mekanisme Penerapan Kantong Plastik Berbayar, disepakati kantong plastik berbayar Rp200 sudah termasuk di dalamnya Pajak Pertambahan Nilai (PPN). Yayasan Lembaga Konsumen Indonesia (YLKI) telah melakukan penelitian mengenai uji coba kebijakan kantong plastik berbayar pada periode 1 Maret-6 April 2016. Hasilnya diketahu bahwa penerapan kebijakan akantong plastik berbayar yang dicanangkan pemerintah belum efektif dalam mengubah perilaku konsumen dalam penggunaan kantong plastik. Kesimpulan YLKI tersebut didasarkan pada data diketahui sebesar 53,6 persen konsumen masih menggunakan kantong plastik seperti biasa, meskipun harus membayar.

Essoussi, L., H. \& Linton, J., D. (2010) melakukan penelitian terkait perilaku konsumen akan produk daur ulang dan seberapa besar konsumen bersedia membayar untuk produk-produk tersebut. Hasil penelitian mereka diketahui bahwa persepsi fungsional risiko merupakan faktor penentu dari harga produk yang bersedia dibayarkan oleh konsumen, pada produkproduk daur ulang. Selain itu hasil penelitian mereka juga mengungkapkan bahwa konsumen akan beralih dari produk daur ulang pada produk baru, dengan rentang harga yang lebih rendah dari produk dengan risiko fungsional. Hasil penelitian ini relevan digunakan sebagai landasan empiris akan kegitan penelitian yang dilakukan, sehingga akan tepat sasaran.

Hasil penelitian dari Essoussi, L., H. \& Linton, J., D. (2010) memiliki keterkaitan dengan rencana penelitian ini, yang juga berupaya untuk menganalisis preferensi konsumen akan kantong belanja ramah lingkungan. Salah satunya dari seberapa besar kesediaan konsumen untuk membayar produk kantong belanja ramah lingkungan. Laroche, M., Bergeron, J. Dan Forleo, G., B. (2001) melakukan penelitian dengan hasil penelitian mengungkapkan bahwa saat ini terdapat beberapa masalah ekologis, yakni perusahaan tidak memiliki tanggung jawab terhadap lingkungan sehingga penggunaan barang-barang yang lebih ramah secara ekologis lebih disukai dan memiliki peranan yang sangat penting. Hasil ini juga memiliki relevansi yang baik untuk digunakan sebagai landasan penelitian yang dilakukan.

Konsumen menempatkan skala kepentingan yang tinggi akan keamanan dan hubungan yang hangat antara satu sama lain. Selain itu konsumen juga telah mempertimbangkan berbagai isu ekologis dalam mengambil keputusan. Ritch, E., Brennan, C., dan Macleod, C. (2009) melakukan penelitian dengan hasil penelitian mereka mengungkapkan terdapat evaluasi kritis dari serangkaian tantangan dalam upaya perilaku konsumen yang perlu diinisiasi dengan baik oleh pemerintah dan bisnis internasional. 


\section{METODE PENELITIAN}

Metode penelitian yang digunakan adalah metode survei yakni melakukan pengumpulan data primer melalui bantuan instrumen angket pada sampel penelitian, yakni responden terpilih yang diharapkan mampu mewakili populasi (Setiawan, 2013, 2015). Populasi penelitian ini adalah masyarakat yang kerap berbelanja pada toko ritel moderen, sedangkan sampel dipilih dengan menggunakan teknik non-probabilitas convenience sampling. Ukuran sampel ditetapkan sebanyak 200 responden, mempertimbangkan representasi secara proporsional dari tiap lokasi penelitian. Pada pengukuran peubah perilaku konsumen, preferensi konsumen dan peluang bisnis, juga diukur dengan teknik pertanyaan tertutup. Namun dalam upaya mengeksplorasi jawaban yang diberikan, dikombinasikan pula dengan tipe pertanyaan terbuka. Hal ini agar responden dapat menarasikan alasan jawaban pernyataan yang diberikan

Karakteristik responden akan dianalisis secara deskriptif kuantitatif dengan melakukan pencacahan data pada data kategorik dan menghitung data pada data numerik. Tanggapan responden pada peubah perilaku konsumen sebelum dilakukan analisis perbandingan, terlebih dahulu dilakukan analisis deskriptif dengan melakukan pencacahan. Setelah dilakukan pencacahan, maka selanjutnya digunakan analisis data sampel berpasangan non-parametrik (Setiawan, 2015). Peubah yang diukur pada penelitian ini dengan definisi operasional peubah yang digunakan adalah sebagaimana disajikan pada Tabel 1.

Tabel 1. Operasionalisasi Peubah

\begin{tabular}{|l|l|l|}
\hline \multicolumn{1}{|c|}{ Peubah } & \multicolumn{1}{|c|}{ Indikator } & \multicolumn{1}{c|}{ Skala Pengukuran } \\
\hline \multirow{4}{*}{$\begin{array}{l}\text { Perilaku konsumen (Consumer } \\
\text { behavior/ CB) }\end{array}$} & Budaya dan sub-budaya (CB 1) & Ordinal \\
\cline { 2 - 3 } & Sosial ekonomi (CB 2) & Ordinal \\
\cline { 2 - 3 } & Pribadi (CB 3) & Ordinal \\
\cline { 2 - 3 } & Psikologi (CB 4) & Ordinal \\
\hline \multirow{2}{*}{$\begin{array}{l}\text { Preferensi konsumen } \\
\text { Consumer prefference/ CP) }\end{array}$} & Preffer (CP 1) & Ordinal \\
\cline { 2 - 3 } $\begin{array}{l}\text { Peluang Bisnis (Business } \\
\text { opportunities/BO }\end{array}$ & Targetference (CP 2) & Ordinal \\
\cline { 2 - 3 } & Dukungan pemerintah (BO 2) & Ordinal \\
\cline { 2 - 3 } & Kerjasama penjualan (BO 3) & Ordinal \\
\cline { 2 - 3 } & Persepsi konsumen (BO 4) & Ordinal \\
\hline
\end{tabular}

\section{HASIL PENELITIAN DAN PEMBAHASAN}

\section{Gambaran Umum Responden Penelitian}

Gambaran umum responden pada penelitian ini ditinjau dari beragam sudut pandang, yakni gender (jenis kelamin), usia, pekerjaan atau profesi yang saat ini dijalani, pendidikan formal, rata-rata penghasilan per bulan, dan status pernikahan. Beberapa karakteristik umum tersebut selanjutnya juga akan dilakukan tabulasi silang, agar mendapatkan gambaran umum yang lebih tepat mengenai karakteristik responden penelitian.

Gender

Gambaran umum responden penelitian ini ditinjau dari sudut pandang gender (jenis kelamin) adalah sebagaimana disajikan pada Tabel 2 berikut. 
Tabel 2. Gender

\begin{tabular}{lrrrrr}
\hline & & Frequency & Percent & Valid Percent & Cumulative Percent \\
\hline Valid & Wanita & 92 & 47,4 & 47,4 & 47,4 \\
& Pria & 102 & 52,6 & 52,6 & 100,0 \\
& Total & 194 & 100,0 & 100,0 & \\
\hline
\end{tabular}

Mengacu pada Tabel tersebut di atas maka dapat diketahui bahwa responden penelitian ini terdiri dari responden wanita sebanyak 92 orang $(47,4 \%)$ dan responden pria sebanyak 102 orang $(52,6 \%)$. Meski terdapat selisih proporsi sebesar 5,2\% namun selisihnya tidaklah besar, sehingga dengan demikian responden penelitian ini dari aspek gender sudah proporsional atau tidak bertendensi hanya pada satu gender tertentu. Hasil yang diperoleh tentu saja akan dapat merepresentasikan perilaku belanja konsumen, di mana aktivitas belanja tidak hanya didominasi oleh wanita namun juga secara proporsional biasa dilakukan pula oleh pria.

Usia

Rata-rata usia responden penelitian adalah 27,36 tahun, dengan selang kepercayaan 95\% diyakini bahwa rata-rata usia responden penelitian akan berkisar antara 26,39 tahun hingga 28,33 tahun. Usia termuda dari responden penelitian ini adalah 17 tahun, sedangkan usia tertua dari responden penelitian ini adalah 49 tahun. Dengan rentang usia 32 tahun diperoleh nilai simpangan baku 6,82 tahun, maka terdapat keragaman usia yang cukup besar dari usia responden penelitian.

\section{Pekerjaan}

Responden penelitian ini sangat didominasi oleh responden yang memiliki latar belakang pekerjaan sebagai pegawai swasta $(55,7 \%)$. Responden yang berprofesi sebagai pegawai negeri sipil (PNS) memiliki proporsi sebesar 17,5\%, profesi wirausaha dengan proporsi sebesar $6,2 \%$, dan pegawai BUMN dengan proporsi sebesar 4,1\%. Adapun responden yang berprofesi sebagai dosen, tenaga kerja Indonesia dan ibu rumah tangga, memiliki proporsi yang sama yakni sebesar $2,1 \%$. Sedangkan responden yang menyatakan tidak atau belum bekerja memiliki proporsi sebesar 10,3\%.

\section{Pendidikan}

Responden penelitian ini didominasi dengan responden yang berlatar belakang pendidikan SMA/sederajat dan disusul kemudian dengan berpendidikan Diploma. Hal ini menjadi cerminan bahwa responden memiliki kecukupan kecakapan pendidikan, untuk dapat memahami setiap butir pertanyaan maupun pernyataan yang diberikan. Hasil uji validitas dan reliabilitas instrumen yang akan disampaikan pada pembahasan berikutnya, diperoleh hasil yang baik dan memuaskan. Hal ini tercapai salah satunya disebabkan responden memiliki latar belakang pendidikan formal yang memadai, sehingga setiap kalimat yang disampaikan pada instrumen dapat dipahami dengan baik.

Penghasilan

Gambaran umum responden penelitian ini ditinjau dari sudut pandang rata-rata penghasilan per bulan yang diperoleh, hasilnya adalah sebagaimana disajikan pada Tabel 3 . 
Tabel 3. Rata-rata Penghasilan per Bulan Responden

\begin{tabular}{llrrrr}
\hline & & Frequency & Percent & Valid Percent & Cumulative Percent \\
\hline Valid & < Rp.2.500.000 & 70 & 36,1 & 36,5 & 36,5 \\
& Rp.2.500.000-Rp.3.499.999 & 48 & 24,7 & 25,0 & 61,5 \\
& Rp.3.500.000-Rp.4.499.999 & 30 & 15,5 & 15,6 & 77,1 \\
& Rp.4.500.000-Rp.5.499.999 & 12 & 6,2 & 6,3 & 83,3 \\
& Rp.7.000.000-Rp.10.000.000 & 18 & 9,3 & 9,4 & 92,7 \\
& $>$ Rp.10.000.000 & 14 & 7,2 & 7,3 & 100,0 \\
& Total & 192 & 99,0 & 100,0 & \\
Missing & System & 2 & 1,0 & & \\
Total & & 194 & 100,0 & & \\
\hline
\end{tabular}

Dengan demikian karakteristik responden penelitian ini cukup proporsional mewakili masyarakat dari berbagai tingkat pendapatan, sehingga respon yang diberikan mencerminkan perilaku konsumen dalam mempersepsikan penggunaan kantong plastik kemasan belanja.

Status Pernikahan

Responden penelitian ini lebih didominasi dengan responden yang belum menikah $(60,8 \%)$ dibandingkan yang sudah menikah $(39,2 \%)$. Hasil ini mengkonfirmasi deskripsi responden berdasarkan usia, yakni rata-rata berusia 27,36 tahun. Rata-rata usia ini masih termasuk usia yang sangat produktif bagi seseorang dalam bekerja. Sehingga cukup masuk akal apabila pada kisaran usia tersebut pada umumnya seseorang memutuskan belum menikah.

\section{Pemetaan Toko Ritel Modem yang Dikunjungi Responden}

Pemetaan toko ritel modern yang kerap atau yang lebih dominan dikunjungi oleh responden penelitian, dari mulai toko ritel modern berjenis minimarket hingga toko ritel modern berjenis hypermarket dijelaskan secara sistematis pada sub bab pembahasan ini.

Toko Ritel Modern Minimarket

Untuk toko ritel modern jenis minimarket dapat diketahui bahwa toko ritel Indomaret dan Alfamart merupakan dua toko ritel modern jenis minimarket yang paling sering dikunjungi oleh responden untuk berbelanja. Hal ini memang tidak dapat dipungkiri, mengingat Indomaret maupun Alfamart merupakan minimarket yang semakin progresif melakukan penetrasi pasar. Keberadaan dua minimarket ini semakin masif memasuki wilayah-wilayah sub urban, bahkan hingga di tingkat kelurahan/desa sudah dapat ditemui dua ritel minimarket ini berdiri saling berdekatan.

Temuan ini perlu ditelaah lebih lanjut, apakah lokasi toko yang saling berdekatan antara Indomaret dengan Alfamart, atau juga dengan toko-toko ritel jenis minimarket lainnya akan membuat konsumen tetap loyal ataukah tidak. Diketahui bahwa konsumen kapan saja dapat memutuskan untuk beralih dari satu merek toko ke merek lainnya. Hal ini dikarenakan selain lokasinya yang saling berdekatan dan ragam produk yang sejenis serta komunikasi promosi yang mirip, sehingga konsumen mudah beralih. 
Masyarakat yang menjadi responden penelitian ini lebih menyukai untuk berbelanja lebih dari satu kali dalam sebulan. Sehingga barang belanjanya dibeli dalam satuan eceran atau tidak dalam jumlah besar, disesuaikan dengan ketersediaan anggaran belanja rumah tangganya masing-masing. Hal ini menjadi cerminan bahwa tingginya penggunaan kantong plastik kemasan belanja, salah satunya disebabkan intensitas belanja konsumen yang berbelanja dalam intensitas berulang.

\section{Toko Ritel Modern Supermarket}

Masyarakat lebih dominan berkunjung berbelanja di Superindo dan Hero, memiliki kecenderungan untuk tidak dominan hanya pada satu merek. Hal ini sebagaimana nampak dari sebaran data yang cukup proporsional dari masing-masing jenis supermarket yang ada. Secara keseluruhan konsumen dapat dikatakan kurang memiliki loyalitas yang tinggi dalam berbelanja di toko modern jenis supermarket. Proporsi jawaban responden pada pertanyaan yang memverifikasi loyalitas konsumen dalam dominasi berbelanja di toko ritel modern jenis supermarket, cukup terdistribusi pada tiap-tiap opsinya.

Intensitas belanja konsumen dalam sebulan di toko ritel modern jenis supermarket lebih kecil dibandingkan intensitas belanja pada ritel minimarket. Hal ini wajar, mengingat keberadaan ritel supermarket pada umumnya berada di kota besar, tidak saling berdekatan, dan memerlukan biaya lebih besar dibandingkan berbelanja ke minimarket yang lokasinya relatif lebih dekat dengan konsumen, berjumlah banyak, sehingga biaya transportasi menuju lokasi lebih murah. Untuk memenuhi kebutuhan sehari-hari, konsumen lebih memilih toko ritel modern jenis minimarket dibandingkan toko ritel supermarket.

Toko Ritel Modern Hypermarket

Perilaku belanja konsumen pada toko ritel jenis hypermarket tersebar pada beberapa merek hypermarket. Dengan demikian pada jenis toko ritel hypermarket tidak terdapat dominasi yang kuat dari salah satu merek hypermarket, dikarenakan sebaran pernyataan responden cukup proporsional khususnya pada ritel Hypermart, Giant, dan Carrefour. Perlu ditelaah lebih lanjut karena tidak adanya dominasi yang kuat dari salah satu toko hypermart, didukung data loyalitas belanja konsumennya.

Diketahui bahwa sebanyak 92 responden $(47,4 \%)$ menyatakan akan tetap dominan berbelanja di hypermarket awal, sebanyak 82 responden $(42,3 \%)$ menyatakan tidak akan tetap dominan berbelanja di hypermarket awal, dan sebanyak 20 responden menyatakan Ya/Tidak atau masih ragu-ragu apakah akan tetap dominan berbelanja di hypermarket awal ataukah berpindah ke hypermarket lain.

Pada toko ritel hypermarket pada umumnya konsumen berkunjung dengan intensitas yang rendah dalam sebulan, yakni 1 hingga 3 kali dalam sebulan. Hal ini dikarenakan toko ritel hypermarket pada umumnya berlokasi di pusat kota dan jumlahnya pun sedikit, menjual ragam produk yang besar dan banyak, dari mulai barang kebutuhan sehari-hari sampai dengan barang-barang elektronik dan barang mewah. Hasil ini mengkonfirmasikan telaah sebelumnya bahwa konsumen cenderung lebih intensif berbelanja di toko ritel minimarket, untuk memenuhi kebutuhannya sehari-hari. 


\section{Perilaku Konsumen dalam Penggunaan Kantong Plastik Kemasan Belanja}

Tahap awal dari analisis perilaku konsumen ritel modern akan penggunaan kantong plastik berbayar, dimulai dari gambaran inisiatifnya dalam membawa kantong belanja sendiri. Hasilnya adalah sebagaimana disajikan pada Tabel 4 di bawah ini.

Tabel 4. Inisiatif Bawa Kantong Sendiri

\begin{tabular}{llrrrr}
\hline & & Frequency & Percent & Valid Percent & Cumulative \\
\hline Valid & Tidak/Belum & 137 & 70,6 & 71,0 & 71,0 \\
& Ya & 56 & 28,9 & 29,0 & 100,0 \\
& Total & 193 & 99,5 & 100,0 & \\
Missing & System & 1 &, 5 & & \\
Total & & 194 & 100,0 & & \\
\hline
\end{tabular}

Mengacu pada Tabel tersebut di atas maka dapat diketahui sebanyak 137 responden $(70,6 \%)$ menyatakan tidak atau belum berinisiatif untuk membawa kantong belanja sendiri, sedangkan sebanyak 56 responden $(28,9 \%)$ menyatakan telah berinisiatif membawa kantong belanja sendiri ketika berbelanja ke toko ritel modern.

Tanggapan rersponden akan pernyataan telah berinisiatif membawa kantong daur ulang sendiri dalam berbelanja, disajikan hasilnya pada Tabel berikut.

Tabel 5. Inisiatif Bawa Kantong Daur Ulang Sendiri

\begin{tabular}{llrrrr}
\hline & & Frequency & Percent & Valid Percent & Cumulative Percent \\
\hline Valid & Tidak/Belum & 140 & 72,2 & 72,2 & 72,2 \\
& Ya & 54 & 27,8 & 27,8 & 100,0 \\
& Total & 194 & 100,0 & 100,0 & \\
\hline
\end{tabular}

Sikap responden akan penggunaan kantong plastik dalam berbelanja, sebelum adanya kebijakan penggunaan kantong berbayar adalah sebagaimana disajikan hasilnya pada Tabel 6 .

Tabel 6. Sikap Masyarakat akan Penggunaan Kantong Plastik Sebelum Kebijakan

\begin{tabular}{|c|c|c|c|c|c|}
\hline & & Frequency & Percent & Valid Percent & Cumulative Percent \\
\hline \multirow[t]{4}{*}{ Valid } & $\begin{array}{l}\text { Meminta kantong plastk } \\
\text { tambahan, jika dianggap } \\
\text { dibutuhkan }\end{array}$ & 160 & 82,5 & 82,5 & 82,5 \\
\hline & $\begin{array}{l}\text { Meminta kantong plastik } \\
\text { tambahan, meski tidak } \\
\text { dibutuhkan }\end{array}$ & 10 & 5,2 & 5,2 & 87,6 \\
\hline & $\begin{array}{l}\text { Tidak meminta kantong } \\
\text { plastik tambahan, meski } \\
\text { dianggap dibutuhkan }\end{array}$ & 24 & 12,4 & 12,4 & 100,0 \\
\hline & Total & 194 & 100,0 & 100,0 & \\
\hline
\end{tabular}


Sedangkan sikap responden akan penggunaan kantong plastik dalam berbelanja, sebelum adanya kebijakan penggunaan kantong berbayar adalah sebagaimana disajikan hasilnya pada Tabel 7.

Tabel 7. Sikap Masyarakat akan Penggunaan Kantong Plastik Sebelum Kebijakan

\begin{tabular}{|c|c|c|c|c|c|}
\hline & & Frequency & Percent & Valid Percent & $\begin{array}{c}\text { Cumulative } \\
\text { Percent }\end{array}$ \\
\hline \multirow[t]{4}{*}{ Valid } & $\begin{array}{l}\text { Meminta kantong plastk } \\
\text { tambahan, jika dianggap } \\
\text { dibutuhkan }\end{array}$ & 100 & 51,5 & 51,5 & 51,5 \\
\hline & $\begin{array}{l}\text { Meminta kantong plastik } \\
\text { tambahan, meski tidak } \\
\text { dibutuhkan }\end{array}$ & 4 & 2,1 & 2,1 & 53,6 \\
\hline & $\begin{array}{l}\text { Tidak meminta kantong } \\
\text { plastik tambahan, meski } \\
\text { dianggap dibutuhkan }\end{array}$ & 90 & 46,4 & 46,4 & 100,0 \\
\hline & Total & 194 & 100,0 & 100,0 & \\
\hline
\end{tabular}

Kesediaan masyarakat untuk membeli kantong belanja ramah lingkungan, adalah sebagaimana disajikan datanya pada Tabel 8 berikut ini.

Tabel 8. Kesediaan Masyarakat Membeli Kantong Belanja Ramah Lingkungan

\begin{tabular}{llrrrr}
\hline & & & & Cumulative \\
& & Frequency & Percent & Valid Percent & Percent \\
\hline Valid & Bersedia & 156 & 80,4 & 80,4 & 80,4 \\
& Tidak Bersedia & 10 & 5,2 & 5,2 & 85,6 \\
& Ragu-ragu & 28 & 14,4 & 14,4 & 100,0 \\
& Total & 194 & 100,0 & 100,0 & \\
\hline
\end{tabular}

Dengan demikian dominan masyarakat menyatakan bersedia untuk membeli kantong belanja ramah lingkungan, di mana kantong tersebut akan digunakan ketika berbelanja di toko ritel modern. Perilaku ini pada masa depan akan menciptakan kepuasan pelanggan sehingga akan membentuk loyalitas dikarenakan citra dan perceived value yang positif (Setiawan, 2014).

\section{KESIMPULAN DAN SARAN}

Untuk toko ritel modern jenis minimarket, responden lebih dominan untuk berkunjung berbelanja di Indomaret dan Alfamart dibandingkan minimarket lainnya. Pada toko ritel modern jenis supermarket, responden lebih dominan berbelanja di Superindo, ADA, dan Hero. Sedangkan pada toko ritel modern Hypermarket lebih dominan berbelanja di Carrefour, Hypermart dan Giant. 
Responden penelitian ini lebih menyukai untuk berbelanja lebih dari satu kali dalam sebulan di minimarket. Sehingga barang belanjanya dibeli dalam satuan eceran atau tidak dalam jumlah besar, disesuaikan dengan ketersediaan anggaran belanja rumah tangganya masingmasing. Intensitas belanja konsumen dalam sebulan di toko ritel modern jenis supermarket lebih kecil dibandingkan intensitas belanja pada ritel minimarket. Hal ini wajar, mengingat keberadaan ritel supermarket pada umumnya berada di kota besar, tidak saling berdekatan, dan memerlukan biaya lebih besar dibandingkan berbelanja ke minimarket yang lokasinya relatif lebih dekat dengan konsumen, berjumlah banyak, sehingga biaya transportasi menuju lokasi lebih murah.

Pada toko ritel hypermarket pada umumnya konsumen berkunjung dengan intensitas yang rendah dalam sebulan, yakni 1 hingga 3 kali dalam sebulan. Hal ini dikarenakan toko ritel hypermarket pada umumnya berlokasi di pusat kota dan jumlahnya pun sedikit, menjual ragam produk yang besar dan banyak, dari mulai barang kebutuhan sehari-hari sampai dengan barang-barang elektronik dan barang mewah. Hasil ini mengkonfirmasikan telaah sebelumnya bahwa konsumen cenderung lebih intensif berbelanja di toko ritel minimarket, untuk memenuhi kebutuhannya sehari-hari.

Perilaku konsumen yang menjadi responden penelitian ini adalah tidak atau belum tergerak untuk berinisiatif membawa kantong kemasan belanja sendiri, ketika berbelanja di toko ritel modern. Namun demikian responden menyatakan bersedia untuk membeli kantong belanja yang ramah lingkungan.

Pada kegiatan penelitian selanjutnya, perlu diukur secara lebih komprehensif akan preferensi konsumen dalam menggunakan kantong belanja ramah lingkungan. Pengukurannya dapat dilakukan dengan menggunakan Rasch model, yang saat ini populer digunakan dalam studi ilmu sosial (Setiawan, Panduwangi \& Sumintono, 2018).

\section{DAFTAR PUSTAKA}

Berman, B., \& Evans, J., R. (2007). Retail Management. New Jersey: Prentice Hall

Chairul, M. (2008). "Kampanyekan Bahaya Kantong Plastik Sejak Dini". http://www.menlh.go.id/kampanyekan-bahaya-kantong-plastik-sejak-dini/ diakses pada tanggal 1 Mei 2016

Ebert, R., J. \& Griffin, R., W. (2009). Bisnis. Alih bahasa Rd. Soemarnagara. Jakarta: Erlangga

Ferrel, O., C. \& Hartline, M., D. (2011). Marketing Strategy. 5th Edition. South-Western: Cenage Learning

Kotler, P., Keller, K., L., (2008). Manajemen Pemasaran, Edisi 13 Jilid 1, Alih Bahasa, Bob Sabran. Jakarta: Erlangga

Laroche, M., Bergeron, J. \& Forleo, G. B. (2001). Targeting Consumers Who Are Willing To Pay More for Environmentally Friendly Products. Journal of Consumer Marketing. Vol. 18. No. 60 pp. $503-520$

Essoussi, L., H. \& Linton, J., D. (2010),"New or recycled products: how much are consumers willing to pay?". Journal of Consumer Marketing. Vol. 27 Iss 5 pp. 458-468 http://dx.doi.org/10.1108/07363761011063358 
Levy, M. \& Weitz, B., A. (2007). Retailing Management. 6th edition. McGraw Hill International

National Geographic Indonesia (2016). "Hal-Hal Seputar Kantong Plastik yang Harus Anda Ketahui”. 19 Februari 2016. http://nationalgeographic.co.id/berita/2016/02/hal-halseputar-kantong-plastik-yang-harus-anda-ketahui diakses pada tanggal 1 Mei 2016

Paul, P., J., \& Olson (2006). Perilaku Konsumen dan Strategi Pemasaran. Edisi Keempat, Jilid I. Jakarta: Erlangga

Ritch, E., Brennan, C., \& MacLeod, C., (2009). Plastic bag politics: modifying consumer behaviour for sustainable development. International Journal of Consumer Studies. pp. 168 - 174 ISSN 1470-6423. http://dx.doi.org/10.1111/j.1470-6431.2009.00749.x

Schiffman, L.G. \& L.L. Kanuk. (1994). Consumer Behaviour. New Jersey: Prentice Hall, Inc., Englewood Cliffs

Setiawan, B., Panduwangi, M., \& Sumintono, B. (2018). A Rasch analysis of the community's preference for different attributes of Islamic banks in Indonesia. International Journal of Social Economics. Vol. 45 Issue: 12, pp.1647-1662, https://doi.org/10.1108/IJSE-07-2017-0294

Setiawan, B. 2015. Teknik Praktis Analisis Data Penelitian Sosial dan Bisnis dengan SPSS. Yogyakarta: Andi

Setiawan, B. (2014). Customer Satisfaction Index Model on Three Level Of Socioeconomic Status In Bogor Case Study: Customer Satisfaction on Branded Cooking Oil Product. ASEAN Marketing Journal, 6(1). Retrieved October 3, 2017, from http://journal.ui.ac.id/index.php/amj/article/view/3609

Setiawan, B. (2013). Menganalisa Statistik Bisnis dan Ekonomi dengan SPSS 21. Yogyakarta: Andi

Sullivan A., \& Sheffrin S.M. (2003). Economics: Principles in action. Upper Saddle River, New Jersey 07458: Pearson Prentice Hall, 2003

Yayasan Lembaga Konsumen Indonesia. (2016). "YLKI: Mayoritas Konsumen Masih Gunakan Kantong Plastik". $13 \quad$ April 2016. http://megapolitan.kompas.com/read/2016/04/13/12320181/YLKI.Mayoritas.Konsumen .Masih.Gunakan.Kantong.Plastik diakses tanggal 1 Mei 2016 